\title{
Towards a Synthesis of Semi-Input-Output and Little-Mirrlees: A Social Cost-Benefit Analysis with Multiplier Effects of An Irrigation Project in Northwest Malaysia
}

\author{
Clive Bell and Shantayanan Devarajan*
}

\section{INTRODUCTION}

An investment project has effects on the incomes of households, firms and government, not only directly through the value added produced by the project itself, but also by inducing additional output through interindustry linkages and expenditures out of the extra incomes accruing to its beneficiaries. The latter, sometimes called the "multiplier" or "downstream" effects of a project, have been discussed in some of the recent literature on social cost-benefit analysis $[6,11]$. These contributions have been concerned with the "multiplier" or "downstream" effects of projects, and with the derivation of shadow prices which capture all such effects in full. If these shadow prices are correctly calculated, so it is asserted, then valuing a project's direct inputs and outputs at these prices yields the right measure of its social profitability. This approach is in the spirit of, and consistent with, that of the various manuals on social cost-benefit analysis $[9,13,16]$.

This paper also deals with the problem of allowing fully for multiplier effects in project evaluation, but approaches it on a different tack. Here, the total (direct and indirect) impact of a project on outputs, incomes, savings and expenditure, which are the elements entering into the calculation of social profits, is derived using a linear model of the economy which is both an extension and an elaboration of Tinbergen's (1966) semi-input-output framework [15]. In other words, we follow the "primal" route of quantity and income flows rather than the "dual" route of shadow prices. This use of the notion of "primal" and "dual" is more than suggestive; for there is an intimate connection between the model developed in this paper

*The authors are associated with the World Bank and the University of California, Berkeley, respectively. The views expressed are those of the authors and do not necessarily reflect those of the World Bank. They are indebted to Charles Blitzer and T. N. Srinivasan for discussions of some of the ideas in this paper but the two gentlemen are not to be held responsible in any way for the use to which the authors have put them. 
and that which underlies Little and Mirrlees [9] and Squire and van der Tak [13]. Although this connection will not be analysed in detail here, the concepts and formulations which the two approaches share in common will be discussed as they appear. Those readers who are more at home with the approach in the manuals should therefore find at least a few welcome points of reference as the paper unwinds, while those who were nurtured on semi-input-output analysis may also find it insightful to have this extension laid out explicitly in its context of social cost-benefit analysis. $^{1}$

To illustrate our technique, we apply it to an ex post evaluation of a largescale irrigation project in Northwest Malaysia, the Muda River Scheme. The main reason for the choice of this particular project is that a semi-input-output model of the project's impact on the Muda region already exists [5]. However, it is also well known that the Muda Scheme has generated substantial downstream effects on the surrounding area -- indicating that its selection for a case study is no mere accident.

The paper is structured as follows. The general model is set out in section I. Its specific application to the analysis of the Muda irrigation project is discussed in section II, since the use of a regional data base, while appropriate in itself, still requires a formulation which captures all relevant effects on the national economy. Section III deals with the estimation of certain parameters which are indispensable for the calculation of social profitability: the border prices of traded goods; and a set of social weights for the valuation of private consumption and savings in terms of uncommitted government income, which is the numeraire. The profitability calculations themselves are deferred to section IV, and the paper concludes with a brief discussion of some salient points.

\section{THE MODEL}

In this section, we present the linear model which is used to estimate the values of all the variables of interest associated with the project's direct and indirect effects. After a brief description of the sectoral classification employed, the various ingredients of the model, i.e. the accounts on which it is built, are taken seriatim. At this point, the model is best thought of as one of a national economy, although its application to a regional context is discussed in the next section.

The model is a variant of Tinbergen's (1966) semi-input-output framework [15]. The M production activities in the economy are divided into two groups:

${ }^{1}$ Wanhill [19] and Kuyvenhoven [8] have tried to synthesize the Little-Mirrlees and semiinput-output approaches without alluding to the "primal-dual" distinction. In another paper [3], we show why their approach may have departed from the spirit of Little and Mirrlees. The [3], we show why their approach may have departed from the spirit of Little and Mirrlees. The 作 pricests. Unfortunately, as noted in Bell and Devarajan, Seton's otherwise commendable paper is marred by a
theoretical flaw. those producing tradeables and those producing nontradeables. ${ }^{2}$ The tradeables sectors have parametrically fixed output levels, i.e. they operate at full capacity; variations in demand are met entirely by changes in net exports. The nontradeables sectors, on the other hand, respond to changes in demand solely by adjusting outputs. These sectors either have excess capacity, in which case they are producing at constant marginal costs, or they add new plant and equipment to satisfy demand, in which case production takes place at constant average costs. It is also important to recall that the classification into tradeables and nontradeables is not necessarily a statement about whether or not these commodities are, in fact, traded. Rather, the distinction is one of the source of supply response, whether it is net exports or domestic output.

To keep the national income accounts consistent, it is necessary to introduce a third type of sector - - for distribution and transportation services - - since export activities, both exogenous and endogenous alike, purchase those services domestically. The full rationale for this modification is given in Bell and Hazell [5]

\section{Material Balances}

The subscripts T, D and N denote the set of tradeables, distribution/transport and nontradeable sectors, respectively. The rows and columns of the fixed coefficient technology matrix, A, are ordered so that it can be partitioned as follows:

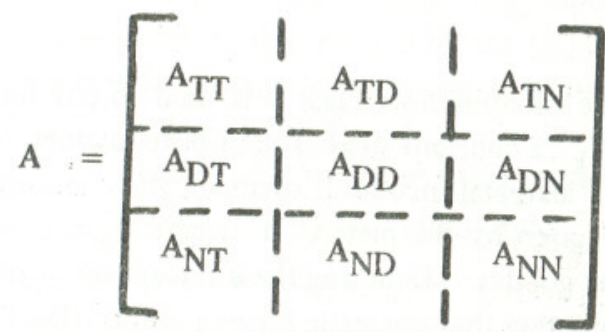

The submatrix $\mathrm{A}_{\mathrm{TN}}$, for example, represents the inputs of tradeables required by the nontradeables sectors when the latter are operating at unit activity levels.

The material balance equations for the economy are:

$$
\begin{aligned}
& X_{T}=A_{T T} X_{T}+A_{T D} X_{D}+A_{T N} X_{N}+C_{T}+G_{T}+J_{T}+E_{T} \\
& X_{D}=A_{D T} X_{T}+A_{D D} X_{D}+A_{D N} X_{N}+C_{D}+G_{D}+J_{D}+\mu E \\
& X_{N}=A_{N T} X_{T}+A_{N D} X_{D}+A_{N N} X_{N}+C_{N}+G_{N}+J_{N}+E_{N}
\end{aligned}
$$

${ }^{2}$ Tinbergen calls these two types of sectors "international" and "national". To highlight the relationship of our approach to that of Little and Mirrlees, we have adopted the terminology
used by the latter. 
where

$\mathrm{X}_{\mathrm{T}}, \mathrm{X}_{\mathrm{D}}, \mathrm{X}_{\mathrm{N}}$ are gross outputs,

$\mathrm{C}_{\mathrm{T}}, \mathrm{C}_{\mathrm{D}}, \mathrm{C}_{\mathrm{N}}$ are consumption demands,

$\mathrm{G}_{\mathrm{T}}, \mathrm{G}_{\mathrm{D}}, \mathrm{G}_{\mathrm{N}}$ are government demands,

$\mathrm{J}_{\mathrm{T}}, \mathrm{J}_{\mathrm{D}}, \mathrm{J}_{\mathrm{N}}$ are private investment demands,

$\mathrm{E}=\left[\mathrm{E}_{\mathrm{T}}, \mathrm{E}_{\mathrm{N}}\right]$ are net exports, and

$\mu \quad$ is the matrix of trade and transport margins on net exports accruing to the domestic economy. ${ }^{3}$

Now equations (1) - (3) are expressed in physical units. By choosing units of physical measure such that all domestic prices are unity, the same equations result if everything were measured in value terms, provided the user price of each commodity (net of transport and distribution margins, which may vary across users) is the same for all users.

\section{Incomes}

The vector of incomes $\mathrm{Y}=\left[\mathrm{Y}_{1}, \ldots, \mathrm{Y}_{\mathrm{L}}\right]$ earned by the $\mathrm{L}$ household types in the economy is determined by direct earnings in production and distributed profits. Let $\mathrm{v}_{\mathrm{kj}}$ and $\omega_{\mathrm{kj}}$ be the direct earnings and dividend payments, respectively, accruing to the $\mathrm{k}^{\text {th }}$ household type for each unit of output produced by industry $\mathrm{j}$. Then,

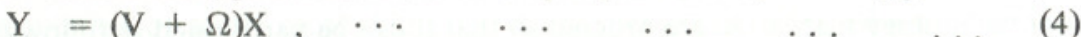$$
\text { where } \mathrm{Y}=\left[\mathrm{X}_{\mathrm{T}}, \mathrm{X}_{\mathrm{D}}, \mathrm{X}_{\mathrm{N}}\right], \Omega=\llbracket \omega_{\mathrm{kj}} \rrbracket, \mathrm{V}=\llbracket \mathrm{v}_{\mathrm{kj}} \rrbracket \text {. }
$$

\section{Consumption}

The gross income of household class $\mathrm{k}$ is used to pay lump-sum taxes, $\overline{\mathrm{T}}_{\mathrm{k}}$, and income taxes, $\tau_{\mathrm{k}} \mathrm{Y}_{\mathrm{k}}$; a constant share, $\mathrm{s}_{\mathrm{k}}$, of post-tax income is saved. Also, a fixed proportion of its marginal income is spent on the consumption of each good. These proportions are given by the matrix $\mathrm{B}$, where $\beta_{\mathrm{ik}}$ is household $\mathrm{k}$ 's marginal propensity to consume good i. Denoting the intercept terms of these consumption functions by $\gamma_{\mathrm{ik}}$, and noting that domestic prices are normalised to unity, we have

$$
\mathrm{C}=\Gamma+\mathrm{B}(\mathrm{I}-\mathrm{s})[(\mathrm{I}-\tau) \mathrm{Y}-\overline{\mathrm{T}}], \quad \cdots \quad \cdots \quad \cdots
$$

where $\Gamma=\llbracket \gamma_{\mathrm{ik}} \rrbracket ;(\mathrm{I}-\mathrm{s}),(\mathrm{I}-\tau)$ are diagonal matrices whose $\mathrm{kk}^{\text {th }}$ elements are $1-\mathrm{s}_{\mathrm{k}}, 1-\tau_{\mathrm{k}}$, respectively; and $\mathrm{C}$ is the $\mathrm{M} \times \mathrm{L}$ matrix of household consumption demands, with $\mathrm{c}_{\mathrm{ik}}$ being household $\mathrm{k}^{\prime}$ s expenditure on good $\mathrm{i}$. Now, the matrix $\mathrm{C}$ is made up of three submatrices $\mathrm{C}_{7}^{*}, \mathrm{C}_{\mathrm{D}}^{*}, \mathrm{C}_{\mathrm{N}}^{*}$ corresponding to the sectoral classification:

${ }^{3}$ As these margins are earned on gross rather than net flows, the above formulation is strictly correct only when there are no competitive imports of characteristic commodities which are exported. In the present application, that is a fair approximation to the observed trade patterns. The transport and distribution margins on noncompetitive intermediate and consumer goods are included in $A_{D T}, A_{D D}, A_{D N}$ and $C_{D}$, respectively. Noncompetitive imports may be placed in category $\mathrm{T}$, the corresponding element of $\mathrm{X}_{\mathrm{T}}$ being zero.

$$
\mathrm{C}=\left[\mathrm{C}_{\mathrm{T}}^{*}, \mathrm{C}_{\mathrm{D}}^{*}, \mathrm{C}_{\mathrm{N}}^{*}\right] \text {. }
$$

The vectors of consumption demands $\left(\mathrm{C}_{\mathrm{T}}, \mathrm{C}_{\mathrm{D}}, \mathrm{C}_{\mathrm{N}}\right)$ in the material balance equations (1) - (3) are the row sums of the matrices $C_{\text {* }}^{*}, C_{D}^{*}, C_{N}^{*}$, since the former set of vectors is obtained by aggregating the columns of the latter matrices over all household types.

\section{Government}

Government derives its revenue from direct taxes, tariff collections and ownership of state corporations.

In addition to income taxes, the government collects corporate taxes which are denoted by

$$
\tau_{F} \zeta^{\prime x}
$$

where $\tau_{\mathrm{F}}$ is the corporate tax rate and $\zeta^{\prime}$ is the vector of profit margins on gross outputs. If $\delta_{\mathrm{G}}^{\prime}$ is the vector of profit margins on state-owned corporations, the government's receipts from these enterprises is $\delta_{G}^{\prime} \mathrm{X}$. Finally, let $\mathrm{P}_{\mathrm{i}}^{*}$ be the ratio of the world price to the domestic producer price of good i. Then government revenue from tariff collections is $\left(\mathrm{P}^{*^{\prime}}-\left(\mathrm{u}^{\prime}+\bar{\mu}^{\prime}\right)\right) \mathrm{E},{ }^{4}$ where $\mathrm{u}^{\prime}$ is a row vector of ones $(1,1, \ldots, 1)$, and $\bar{\mu}$ is the vector of total trade and transport margins on net exports which accrue to domestic producers.

We now assume that the government spends its entire revenue. The bundle $(\mathrm{G})$ of government purchases is given by: a vector $\left(\mathrm{C}_{\mathrm{G}}\right)$ of obligatory purchases for current consumption (education, health, etc.), a vector (K.) of exogenous outlays on investment goods (project-related expenditure), and a residual whose composition is fixed. The latter is given by the vector $\Phi$, where $\phi_{\mathrm{i}}$ is the government's outlay on goods from sector $i$ out of each dollar of the revenue remaining after current consumption and project-related outlays. We have, therefore,

$$
\mathrm{G}=\mathrm{K}+\mathrm{C}_{\mathrm{G}}+\Phi \mathrm{u}^{\prime}\left(\mathrm{G}-\mathrm{K}-\mathrm{C}_{\mathrm{G}}\right), \quad \ldots \quad \ldots \ldots
$$

where $\mathrm{G}=\left[\mathrm{G}_{\mathrm{T}}, \mathrm{G}_{\mathrm{D}}, \mathrm{G}_{\mathrm{N}}\right]$.

Equating the government's purchases to its revenue yields

$$
u^{\prime} G=t^{\prime} Y+u^{\prime} \bar{T}+\left(\tau_{F} \zeta^{\prime}+\delta^{\prime}\right) X+\left(P^{*^{\prime}}-\left(u^{\prime}+\bar{\mu}^{\prime}\right)\right) E, \ldots
$$

where $\mathrm{t}^{\prime}=\left(\tau_{1}, \ldots, \tau_{\mathrm{L}}\right)$.

It is now necessary to relate government revenues (and purchases) as defined here to the concept of "uncommitted social income, measured in terms of convertible foreign exchange", which is the numeraire advocated by Little and Mirrlees

${ }^{4}$ When the sum of the trade and distribution margins $\left(\bar{\mu}_{\mathrm{j}}\right)$ on net exports of a commodity accrue to domestic producers, the ex-tariff f.o.b. price of the exports is $\left(1+\bar{\mu}_{\mathrm{j}}\right)$. 
[9, pp. 145-151]. In our model, the impact of a project on government revenue in a particular time period is simply the change in $u^{\prime} \mathrm{G}$ associated with the project, i.e. the difference between $u^{\prime} G$ in equilibrium with the project and $u^{\prime} G$ in equilibrium without the project. As $\mathrm{K}$ is the set of government purchases required to put the project into effect, the change in $\mathrm{u}^{\prime}\left(\mathrm{G}-\mathrm{K}-\mathrm{C}_{\mathrm{G}}\right)$ arising from the project will measure the change in social income available for commitment to other uses only if there is no change in public consumption, $\mathrm{C}_{\mathrm{G}}$. Furthermore, as the model's formulation of the international trade regime is implicitly that of the "small country" case, this change in "uncommitted social income" will indeed take the form of a change in the holdings of foreign exchange reserves provided the notion of "uncommitted" is not taken too literally. ${ }^{5}$ Since the government can exchange one tradeable good against another in any quantity it desires at fixed world prices, its marginal income is in effect "uncommitted", in the sense that the composition of its marginal purchases does not matter, if there are no allocations for the purchase of nontradeables, i.e. if $\Phi_{\mathrm{D}}$ and $\Phi_{\mathrm{N}}$ are both zero. Hence, by setting all $\phi_{\mathrm{i}}{ }^{\prime} \mathrm{s}$ in equation (6) equal to zero, except that for noncompetitive imports (which will be unity), and by keeping $\mathrm{C}_{\mathrm{G}}$ invariant with respect to $\mathrm{K}$, the project's effects on "uncommitted social income, measured in terms of convertible foreign exchange" is simply the associated change in $\mathrm{u}^{\prime}\left(\mathrm{G}-\mathrm{K}-\mathrm{C}_{\mathrm{G}}\right)$.

\section{Savings and Investment}

- A crucial feature of the model developed here is that private investment is assumed to be financed solely by private (household and corporate) savings. While this is a plausible assumption in a national setting, it introduces certain difficulties in the context of a regional economy, which will be discussed in a later section.

Taking corporate savings to be equal to undistributed net-of-tax corporate profits, we have:

$$
u^{\prime} J=u^{\prime} S+\left[\left(1-\tau_{F}\right) \zeta^{\prime}-u^{\prime} \Omega\right] X,
$$

where $\mathbf{J}=\left[\mathrm{J}_{\mathrm{T}}, \mathrm{J}_{\mathrm{D}}, \mathrm{J}_{\mathrm{N}}\right]$ and $\mathrm{S}=\left[\mathrm{S}_{1}, \ldots, \mathrm{S}_{\mathrm{L}}\right]$, with $\mathrm{S}_{\mathrm{k}}=\mathrm{s}_{\mathrm{k}}\left[\left(1-\tau_{\mathrm{k}}\right) \mathrm{Y}_{\mathrm{k}}-\overline{\mathrm{T}}_{\mathrm{k}}\right]$.

Investment demand in this model has two components. First, "balancing" investment may be needed to release capacity bottlenecks in the nontradeables sectors as the economy moves from one steady state to another: this is denoted by the vector H. Secondly, there is "voluntary" investment, which is taken to be the residual investible funds allocated in fixed proportions $\left(\psi_{\mathrm{i}}\right)$ across the various sectors. Thus,

$$
\mathrm{J}=\mathrm{H}+\Psi \mathrm{u}^{\prime}(\mathrm{J}-\mathrm{H}) \cdot \quad \ldots \quad \ldots \quad \ldots \ldots
$$

${ }^{5}$ This is a consequence of the fact that the economy is in balance-of-payments equilibrium, as is shown below in this section.
It should be noted that in order to value private investment in the social costbenefit calculation, we must know the distribution of investment demands among households (since, presumably, investment by poor households will be socially more valuable than that by rich ones). However, since our data do not permit this level of disaggregation, we are forced to represent private investment by a single vector, implicitly assuming that the composition of investment demand is the same across households.

The particular set of assumptions we have made also guarantees balance of payments equilibrium for the economy, that is, $\mathrm{P}^{*^{\prime}} \mathrm{E}=0$. This is readily seen by adding equations (1) - (9) and setting prices equal to costs at domestic prices.

Now the linear system (1) - (9) has $4 \mathrm{M}+\mathrm{L}$ linearly independent equations in $5 \mathrm{M}+\mathrm{L}$ unknowns. To solve the system, therefore, we must specify $\mathrm{M}$ of the unknowns as exogenous. For tradeable goods, we fix the level of outputs, $\mathrm{X}_{\mathrm{T}}$, and solve for $\mathrm{E}_{\mathrm{T}}$; whilst for the other two subsets of sectors, we specify $\mathrm{E}_{\mathrm{D}}$ and $\mathrm{E}_{\mathrm{N}}$, and solve for $\mathrm{X}_{\mathrm{D}}$ and $\mathrm{X}_{\mathrm{N}}$.

\section{Social Cost - Benefit Analy sis}

Schematically, the above model can be represented as follows:

$$
\mathrm{Z}=\mathrm{A}^{*} \mathrm{Q}+\mathrm{A}^{* * \mathrm{u}}, \cdots
$$

where $\mathrm{Q}$ and $\mathrm{Z}$ are the vectors of exogenous and endogenous variables, respectively, and the system's parameters enter into the elements of the matrices $A^{*}$ and $A^{* *}$. For example, $\mathrm{Q}$ contains the output levels of the tradeables sectors, whereas $\mathrm{Z}$ contains their corresponding net export levels. By solving for $\mathrm{Z}$, given $\mathrm{Q}$ in (10), we take into account all multiplier effects consistent with the model.

To determine the impact of a project, we first specify the values taken by the exogenous variables, $\mathrm{Q}$, for the economy with the project, and solve for the endogenous variables, $Z$. Next, we draw a hypothetical picture of the economy as it would have been in the absence of the project. If, as is usual, the project has an effect on the technology employed in its own sector, or even elsewhere in the economy, one or both of the matrices $\mathrm{A}^{*}$ and $\mathrm{A}^{* *}$ will be different in the hypothetical, "without-project" case from the "with-project" case. With the new technologies and the exogenous variables $Q^{\circ}$ specified for the "without-project" case, equation (10) can be solved for $Z^{\circ}$, the values of the endogenous variables when the project is not undertaken. The difference between the ordered pairs of vectors $(Q, Z)$ and $\left(Q^{\circ}, Z^{\circ}\right)$, then, represents the project's impact on the economy.

Now, how can the project's impact on outputs, incomes, savings, etc. be used to determine "social profit", the contribution of the project to social welfare in a given year? The arguments of the Little-Mirrlees social profit function are: private consumption; private savings over and above that needed to finance the balancing investments in the nontradeables sectors; and uncommitted public income. Here, it will be assumed that the weights for private savings and consumption relative to uncommitted social income (the numeraire) are estimated so as to remain constant 
over the relevant ranges of these variables, ranges which may be quite large. Hence, the social profit, $\Delta \mathrm{U}$, associated with the project for a unit time period is given by

$$
\begin{aligned}
\Delta U= & u^{\prime}\left(G-G^{\circ}-K\right)+u^{\prime}\left(C-C^{\circ}\right) \lambda+\xi^{\prime}\left(S-S^{\circ}\right) \\
& +\xi_{F}\left[\left(1-\tau_{F}\right) \zeta^{\prime}-u^{\prime} \Omega\right]\left(X-X^{\circ}\right)-\xi_{H^{H}} \cdot \ldots
\end{aligned}
$$

where the vectors $\lambda$ and $\xi$ denote, respectively, the social valuations of a unit increase in the levels of consumption and savings for each of the household classes; $\xi_{\mathrm{F}}$ is the social valuation of a unit of retained corporate profits; and $\xi_{\mathrm{H}}$ is the social valuation of the savings which finance the balancing investment, $\mathrm{H}$, whose composition by source may differ from that for savings as a whole.

It is important to note that (11) departs from Little and Mirrlees in that the weights $\lambda, \xi, \xi_{\mathrm{F}}$ and $\xi_{\mathrm{H}}$ are applied to private consumption and savings measured at market prices as opposed to accounting prices. In their discussion of this choice, Little and Mirrlees [9, pp. 236-237] seem to be concerned principally with the fact that different consumers may pay different prices for the same good. Faced with this difficulty, they suggest, as a short-cut, that consumers' expenditures be valued at accounting prices. Although we do not find this a very appealing suggestion for making 'baskets' of goods purchased at different market prices comparable with one another, it is the only strictly correct way of comparing consumers' expenditures with uncommitted social income unless the consumer's consumption conversion factors happen to be the same. However, as Little and Mirrlees recognise, an assessment of equity among consumers requires comparisons of their expenditures (or incomes) at market prices, even though this may mean that incomes of two people which differ greatly at market prices may differ little at accounting prices - and hence be of roughly the same social value if their short-cut method is adopted.

We have formulated exactly this issue of equity among consumers at the possible cost of introducing some errors into the valuation of their expenditure relative to the numeraire. Indeed, since the method advanced here is designed to finesse the task of estimating accounting prices for nontradeables and shadow wage rates, we have no choice in the matter. As for the possibility that different people may pay different prices for the same good, the region under study is blessed with a good transportation system. Moreover, the provincial capital is both modest in scale and readily accessible to all rural households, so that urban and rural cost of living indexes probably differ little.

To complete the evaluation of the project, the stream of social profits, as given by equation (11), generated by the project throughout its lifetime is discounted at the accounting rate of interest.

\section{APPLYING THE MODEL TO THE MUDA IRRIGATION PROJECT}

The model set out in section II describes the flows within a national economy and those to and from the rest of the world. But in applying the model to evaluate the Muda scheme, we employ data pertaining to a particular region, namely, the project's impact region. The region encompasses the state of Perlis and about half of Kedah, in northwest Malaysia. The rationale for this regional, rather than a national, data base is that a social accounts matrix for the impact area has already been estimated [4] and, indeed, a semi-input-output model has been applied to it [5]. However, although the basic structure of the model in section $I$ is preserved if the data pertain to a region, some additional assumptions must be made if the results are to be interpreted correctly.

First, there are primary commodities which do not normally enter international trade until they are processed, but which are shipped in raw form from the producing region to other regions for processing. In the present case, there are two such goods: paddy and smoked rubber sheet. Until the advent of irrigation in 1970, the region's net exports of paddy were roughly zero. Thereafter, the surge in the region's paddy output resulted in substantial exports of paddy to rice mills in southem Kedah and Province Wellesley, as the capacity of the region's milling sector did not expand rapidly enough to keep pace. Only in the late 'seventies was the region's capacity sufficient to mill the whole of the region's paddy crop. As for rubber, less than 15 percent of the output of the region's smallholders and estate sectors is processed within the region itself. Strictly speaking, therefore, these two commodities should be treated as "tradeables" with respect to the region. Yet, the processing of paddy and rubber generates value added within the Malaysian economy, and the multiplier effects of this value added would go unaccounted for if the model were applied literally. To correct for this, processing activities outside the region are treated in the model as if they took place inside the region, which entails the assumption that technologies, the distributions of value added among households and the levels of household incomes do not vary across regions. As this comparison involves northern Kedah on the one hand and southern Kedah and Province Wellesley on the other, all of them rather poor regions, the accompanying assumption seems defensible.

Secondly, by no means is the whole of private savings invested in the region itself. The outflow of private capital from the region, much of it through the banking system, was especially large in 1972 and for some years thereafter. Very little is known about the uses to which these savings are put, and for want of anything better, it has been assumed that they are used to finance the purchase of a bundle of investment goods whose composition is the same as that of the region's own investment activities. As all private savings are invested in the model presented above, the procedure adopted here is tantamount to incorporating within the region those activities making deliveries to meet investment demands outside the region which are also financed by the region's savings.

Now both of these 'enlargements' of the region's activities, whether by raising output, and hence income, in the tradeable sectors, or by increasing the demand for investment goods from the nontradeable sectors, will lead to further rounds of in- 
creases in incomes and the output of the nontradeable sectors. Thus, the results from the model will not square with those for the Muda region reported in Bell and Hazell [5], which are derived from a closely related semi-input-output model featuring exports of paddy and smoked rubber sheet as well as exogenously fixed investment. In particular, value added will be much higher in the 'extended' region described here. Moreover, as there is a rise in output in all the sectors producing nontradeables in all of the other spatial regions of the economy thus affected, the earlier assumption of homogeneous technologies, distributions of value added among households and household income levels is not only vital, but also far stronger than it appears to be at first sight. Be that as it may, the data admit of nothing better. Certainly, such assumptions of homogeneity are every bit in keeping with those employed in estimating 'national' shadow prices in the literature on social cost-benefit analysis.

A third consideration in the interpretation of the model's results rises from the fact that there is a stream of seasonal workers into the Muda region during the paddy harvesting period. Some of these agricultural workers come from southern Kedah and Kelantan, but others come from Thailand. The former belong to households whose income levels are, in all probability, at best equal to those enjoyed by landless paddy farm households in the Muda region. Hence, at one extreme, the migrants' seasonal earnings could be simply lumped in with those of Muda's landless households, on the assumption that the output foregone in their home regions is zero. Alternatively, it can be assumed that their seasonal earnings in Muda are exactly equal to the output foregone elsewhere in the economy, both valued at market prices. The assumption underlying the results presented below rests somewhat uneasily in between, inasmuch as all payments to seasonal workers, Malay and Thai alike, are treated as imports used in paddy production. This is undeniably rough and ready, but the sums involved are small and hardly worthy of more elaborate treatment. However, there is one respect in which payments to Malay and Thai seasonal workers must be distinguished: presumably the Malaysian government attaches no social value to extra income enjoyed by Thai workers, whereas it ought to smile on additional income accruing to poor Malay agricultural workers. For this reason, payments to Malay seasonal workers must feature in an appropriate way in the calculation of the project's stream of social profits.

With this classification, the next step in the calculation of the project's social profitability is to set up a pair of vectors of exogenous variables for each year of the project's expected lifetime, one denoting the estimated actual values of such variables and the other their estimated values in the hypothetical event that the project had not been undertaken. Construction work on the project began in a small way in 1965 , reached a peak in 1967 and 1968, and then tailed off steadily to completion in 1972. Irrigation commenced on a small scale in 1970. By 1972, about threequarters of the project command area was served, and in 1974 the project attained full maturity. However, 1974 was also an abnormal year where the ratio of the domestic to the world price of rice is concerned. The ratio ruling in 1975 seems domestic to the world price of rice is concerned. more representative of the conditions likely to hold over the project's lifetime. Hence, assuming that a steady state ruled after 1975, this chrc to entail the estimation of no fewer than 22 separate vectors of exogenous variables - a daunting task indeed.

Fortunately, it turns out that during that part of the project construction pewhen no output is produced, it suffices to estimate the two sets of exogenous variables for just one year. For recall from equation (10) that so long as $\mathrm{A}^{*}$ and $A^{* *}$ are unchanged, i.e. there are no changes in technology and expenditure propensities, the change in the levels of the endogenous variables is given by:

$$
\mathrm{Z}-\mathrm{Z}^{\circ}=\mathrm{A}^{*}\left(\mathrm{Q}-\mathrm{Q}^{\circ}\right)
$$

Now if during this phase of the project, the members of the sequence of exogenous vectors $\left[\mathrm{Q}-\mathrm{Q}^{\circ}\right]$ are scalar multiples of one another - in this case, $\mathrm{Q}-\mathrm{Q}^{\circ}$ is the project's demands for investment deliveries from the construction sector - - the members of the sequence $\left[\mathrm{Z}-\mathrm{Z}^{\circ}\right]$ are likewise. Hence, once the sequence of

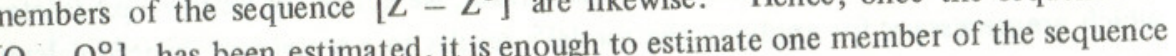
$\left[\mathrm{Q}-\mathrm{Q}^{\circ}\right]$ has been estimated, it is enough the purpose of $\left[\mathrm{Z}-\mathrm{Z}^{\circ}\right]$ in order to arrive at the rest. The year actually chosen for this purpose is 1967 , in keeping with the discussion in [5].

Once the project begins to produce an output stream, however, $\mathrm{A}^{*}$ will change continuously until the project reaches maturity. Hence, in principle, it is necessary to estimate

$$
\mathrm{Z}-\mathrm{Z}^{\circ}=\mathrm{A}^{*} \mathrm{Q}-\mathrm{A}^{* \circ} \mathrm{Q}^{\circ} \quad \cdots \quad \cdots \cdots
$$

for all years after 1970 , the matrix $\mathrm{A}^{* *}$ being unaltered by the project.

In the present case, the pair of vectors $\left(\mathrm{Q}, \mathrm{Q}^{\circ}\right)$ had already been estimated for the years 1967, 1972 and 1974 in connection with the model in [5]. To keep the amount of additional work within reasonable bounds, it was decided to estimate ( $A^{*}$, amount of additional work within reasonable boun in $\left.A^{* \circ}\right)$ and $\left(Q, Q^{\circ}\right)$ for 1970 alone and to use linear interpolation in order to arrive the values of relevent variables for the intervening 'transitional' years, 1971 and 1973. Naturally, the estimation procedure for these sets of variables for 1970 followed closely that in the Bell-Hazell paper [5]. In brief, the paddy production technolo(a) to be output-weighted averages of the corresponding technologies for 1967 and 1972. Apart from the obvious difference

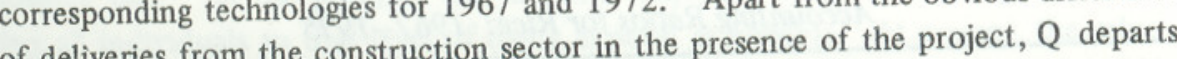
of deliveries from the construction sector in the presence of the project, Q depation and extra from $\mathrm{Q}^{\circ}$ by virtue of the additional paddy throughput in the region's rice mills. There is a small fall in essing as labour is drawn off into paddy harvesting activities. Also, exogenous taxes change somewhat as farmers benefit from irrigation subsidies and rising regional activities swell tax receipts from vehicle and business registration fees. 
Finally, it should be noted that the model employed here features two sets of parameters, namely, $\Phi$ and $\Psi$, which are not found in [5]. As already explained in section I, residual government purchases are allocated entirely to noncompetitive imports. The vector $\Psi$ denotes the composition of demand for investment goods by the private sector after all necessary purchases of 'balancing' investments have been made. A critical assumption underlying the estimation of $\Psi$ is that the share of noncompetitive imports in total outlays on such investments stayed constant at its 1972 level. That being so, $\Psi$ varied little up to 1970 , thereby keeping $A^{*}$ invariant to all intents and purposes. It showed only slight year-to-year variation thereafter, so it seems reasonable to assume that there were no fluctuations after 1974, when the project attained its steady state configuration.

\section{ESTIMATION OF NATIONAL PARAMETERS FOR SOCIAL COST-BENEFIT ANALYSIS}

The estimation of the parameters of the model [equations (1) - (9)] has been described in [5]. Our additions to that model, namely, the vectors $\Phi$ and $\Psi$, were discussed in the preceding section. In this section, we derive the national parameters which are necessary for applying the model's results to a social cost-benefit calculation.

Four sets of national parameters are used in our calculus: (i) the accounting ratios of traded goods, that is the ratio of their world price to their domestic price; (ii) the social valuation, in terms of uncommitted social income, of a unit of private consumption enjoyed by each household class (the vector $\lambda$ ); (iii) the social valuation of private savings in terms of the numeraire ( $\xi$ ); and (iv) the accounting rate of interest. These are taken seriatim.

Veitch [1.7] estimates accounting ratios for our ten tradeable sectors for 1974 Except for the two rice milling sectors, we assume these ratios were the same throughout the period under study. Since the ratio of the world to the domestic price of rice changed considerably over the period 1967-1975, and rice is the sole direct output of the project, the accounting ratio for rice was estimated separately for each year in this period. This set of accounting ratios is laid out in Table 1 .

Table 1

Accounting Ratios for Rice: 1967-1975

\begin{tabular}{lllllllll}
\hline 1967 & 1968 & 1969 & 1970 & 1971 & 1972 & 1973 & 1974 & 1975 \\
0.867 & 0.914 & 0.905 & 0.895 & 0.776 & 0.732 & 0.716 & 1.110 & 0.901
\end{tabular}

Source: $[7]$ and $[10]$.
The two unobservable sectors in our economy which export significant amounts (albeit in exogenously fixed quantities) are "other agriculture"and "manufacturing n.e.c.". Their accounting ratios were estimated by using ratios of those categories in Veitch which correspond most closely to their characteristic commodities. Finally, the accounting ratio for noncompetitive imports was derived by taking a weighted average of the different imports, the weights being obtained from the original SAM tableau. The complete set of accounting ratios for 1974 is given in Table 2 .

Table 2

Accounting Ratios for 1974

\begin{tabular}{lc}
\multicolumn{1}{c}{ Sector } & Accounting Ratio \\
\hline Commercial rice mills & 1.11 \\
Small rice mills & 1.11 \\
Food processing & 0.91 \\
Fish processing & 1.19 \\
Padi production & $1.00^{*}$ \\
Fishing & 1.19 \\
Estates rubber & 1.22 \\
Smallholder rubber & 1.22 \\
Rubber processing & 1.22 \\
Other agriculture & 0.91 \\
Sawmilling & 1.32 \\
Manufacturing n.e.c. & 0.80 \\
Noncompetitive imports & 0.90 \\
\hline
\end{tabular}

*No paddy is in fact exported, and so the value of unity is used solely for accounting requirements.

To estimate $\lambda$, the set of social weights for household consumption, two parameters are needed: $\bar{c}$, the so-called critical per capita consumption level, at which a unit of additional consumption (valued at market prices) is just as valuable socially as

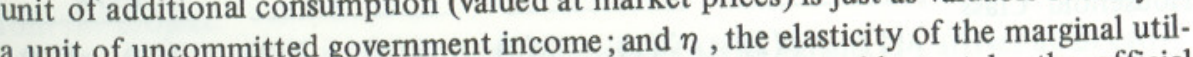
ity of consumption. Where $\overline{\mathrm{c}}$ is concerned, it is reasonable to take the official ity of consumption. Where c is concerned, of the bring all individuals to that level of living as soon as possible. At present, the value of $\bar{c}$ in 1972 prices is $M \$ 375.5$ per annum [18, p. 29], which is about one-third of per capita GDP. It is difficult to be so definite about $\eta$. Following a wellper capita GDP. established tradition in this literature, two valu from a logarithmic utility function and is mildly egalitarian; and two, which corresponds to Atkinson's [2] equally distributed equivalent income being the harmonic mean of all incomes and is quite strongly egalitarian. 
Now as indicated by Bell and Hazell [5], the project brought about large changes in the per capita consumption levels of the five classes of households. Hence, the concavity of the utility function implies that potentially serious errors will arise if $\lambda$ is estimated at the steady state values of household consumption. Instead, we proceed as follows. In view of equation (11), two additional parameters of the utility function may be fixed. First, the marginal social utility of a unit of private consumption at $\overline{\mathrm{c}}$ should be unity. Secondly, the absolute social utility attached to a private consumption level of $\bar{c}$ should be $\bar{c}$. Hence, we have, for $\eta=1$ and $\eta=2$, respectively,

$$
\begin{aligned}
& \mathrm{V}(\mathrm{c})=\overline{\mathrm{c}}\left[1+\log _{\mathrm{e}}(\mathrm{c} / \overline{\mathrm{c}})\right] \ldots \ldots \\
& \mathrm{V}(\mathrm{c})=\overline{\mathrm{c}}[2-\overline{\mathrm{c}} / \mathrm{c}] \quad \cdot \quad \ldots \quad \ldots \quad \ldots \quad \ldots \quad \ldots
\end{aligned}
$$

The value of $\lambda$ arising from a movement from $c^{\circ}$ to $c$ is, therefore,

$$
\lambda=\left[\mathrm{V}(\mathrm{c})-\mathrm{V}\left(\mathrm{c}^{\circ}\right)\right] /\left[\mathrm{c}-\mathrm{c}^{\mathrm{o}}\right] \cdot
$$

The per capita consumption levels of the various classes of household for 1967 and 1974, both with and without the project, are taken from [5], while those for 1972 with the project have been estimated directly in the course of constructing the SAM for that year. Those for 1970 and 1972 (without the project) were derived by linear interpolation. The resulting values of $\lambda$ are set out in Table 3. There is no call for the (spurious) accuracy of similar calculations for the intervening years. Up to 1970 , the values of $\lambda$ for 1967 will do; those for 1972 will be applied to 1971 ; and those for 1974 are assumed to hold for 1973 and all years thereafter.

\begin{tabular}{|c|c|c|c|c|c|c|c|c|c|}
\hline \multirow{2}{*}{\multicolumn{2}{|c|}{ Household Class }} & \multicolumn{2}{|c|}{1967} & \multicolumn{2}{|c|}{1970} & \multicolumn{2}{|c|}{1972} & \multicolumn{2}{|c|}{1974} \\
\hline & & $\lambda(1)$ & $\lambda(2)$ & $\lambda(1)$ & $\lambda(2)$ & $\lambda(1)$ & $\lambda(2)$ & $\lambda(1)$ & $\lambda(2)$ \\
\hline 1 & Landless & 3.25 & 10.53 & 2.62 & 6.90 & 2.29 & 5.39 & 2.14 & 4.70 \\
\hline 2 & Labour abundant & 2.37 & 5.63 & 2.11 & 4.45 & 1.83 & 3.41 & 1.61 & 2.63 \\
\hline 3 & Land abundant & 1.54 & 2.36 & 1.38 & 1.92 & 1.19 & 1.43 & 1.03 & 1.08 \\
\hline 4 & Nonproject farm & 1.75 & 3.09 & 1.59 & 2.55 & 1.39 & 1.94 & 1.25 & 1.42 \\
\hline 5 & Nonfarm & 0.78 & 0.61 & 0.73 & 0.53 & 0.63 & 0.41 & 0.53 & 0.29 \\
\hline
\end{tabular}

Table 3

Social Weights for Household Consumption at Market Prices

$\lambda(\eta)$ denotes the value of $\lambda$ evaluated at $\eta=1,2$
In placing a social value on a household's savings, Little and Mirrlees [9, p. 243] make the suggestion that, as a short-cut, the weight attached to a unit of savings by household class $\mathrm{k}, \xi_{\mathrm{k}}$, be taken as half way between unity, i.e. the weight for uncommitted government income, and the weight for a unit of consumption by that household. Of course, if the latter exceeds unity, the rule of thumb implies that the households concerned are deemed to be saving "too much", given their poverty. Using the Little-Mirrlees rule of thumb, the sets of weights for household savings corresponding to those for consumption follow at once from Table 3. As for corporate savings, which are ultimately distributed to very rich household or foreign nationals, these will generally have a very low social valuation. In the light of the social weight attached to the savings of nonfarm households, perhaps a weight of 0.2 for corporate savings would not be objectionable. Finally, there is the matter of the social valuation of the savings needed to finance the set of "balancing" investments, $\mathrm{H}$. Most of these investments were undertaken in the nonfarm sector of the economy between 1970 and 1974, by incorporated and unincorporated enterprises alike, while others took the form of house construction or improvement by farm households. Accordingly, in rather rough and ready fashion, the value of $\xi_{\mathrm{H}}$ is taken to be 0.7 .

The argument advanced above rests on the notion that all households have access to a perfect capital market and so earn the same real rate of return on their savings. In practice, poorer households in the Muda region are likely to place their financial savings in bank accounts yielding zero or negative real rates of return, to the advantage of affluent borrowers who have access to highly profitable investment opportunities. If, in the extreme, all household savings were placed in the banking system and then lent to the government, to the richest class of households, or to private corporations, then the social weight attached to all savings, irrespective of source, would lie somewhere in the range of those for these three institutional categories, depending on their shares in the total volume of lending. Very little is known about these matters, and it is profitless to attempt a refined calculation. Moreover, since the purpose of setting up this extreme case is to establish a parameter value for sensitivity analysis, a social weight of 0.7 for all private savings should provide a plausible lower bound on the valuation of this stream of outcomes flowing from the project.

Turning to the accounting rate of interest (ARI), Anand [1] arrives at an estimate for Malaysia of ten percent. This is close to the rate at which Malaysia can borrow from the world market. As the country's balance of payments position was quite strong in the period 1967-1974, and as foreign reserves have remained high since then, a nominal rate of nine or ten percent appears plausible. However, the model set out here is formulated in constant (domestic) prices. Adjusting for an average annual inflation rate of five percent and assuming exchange rate stability against an appropriate basket of currencies, we estimate the ARI to be around five percent. On the other hand, it may be felt that public sector projects should have 
a higher rate of return than the marginal cost of foreign borrowing, so that this figure of five percent is probably a lower bound. To reflect this consideration, we perform sensitivity experiments using figures of five, ten and twenty percent for the ARI.

\section{SOCIAL COST-BENEFIT CALCULATIONS}

Recalling equation (11), the stream of social profits generated by the project is made up of various elements: the project's effects on household consumption and savings, on retained corporate profits and on government income. It is worthwhile setting out the individual trajectories of these elements before weighting them together to yield the time path of social profits, for the positive basis of the subsequent normative aggregation is then clear.

The trajectories are laid out in Table 4. There is nothing very startling about them, given the nature of the project. In the construction phase, the government made large outlays on construction, which accrued, in the first instance, as incomes to nonfarm households and corporations, both domestic and foreign. Agricultural households participated only marginally in this activity and the extra activity in other domestic sectors induced in its wake. After the project came on stream in 1970 , the incomes of agricultural households rose rapidly, with expenditures out of these incomes boosting nonfarm incomes and corporate profits as project construction wound down. Government income increased too, as revenues from income and indirect taxes increased by more than enough to offset the losses arising out of the effective protection afforded to the paddy sector in all years but 1974 (see Table 1). The outlays on "balancing" investments are the higher of the two (rather rough) estimates discussed in [5], just to be on the safe side. The various flows for 1975 are assumed to be the steady state values of relevant variables for the rest of the project's life.

The stream of social profits associated with the flows in Table 4 has been calculated under four sets of assumptions about the social valuation of household consumption, savings and corporate profits. These correspond to two values of the elasticity of the marginal utility of consumption and two methods of placing a social valuation on household savings and retained corporate profits, as already discussed in the previous section. By way of comparison, and to satisfy those who would have no truck with distributional weights to value private consumption and savings in terms of govemment income, the stream of social profits has also been claculated with all such weights set to unity.

These alternative streams are set out in Table 5. In all cases, the project's net present social value is handsomely positive at an accounting rate of interest of 10 percent, and it can get by even at 20 percent. Thus, the great improvements in the material standards of people living in the Muda region which have been brought about by the project -- at once evident to the casual observer -- are complemented by the project's high social profitability. Interestingly enough, the vlaue of $\eta$

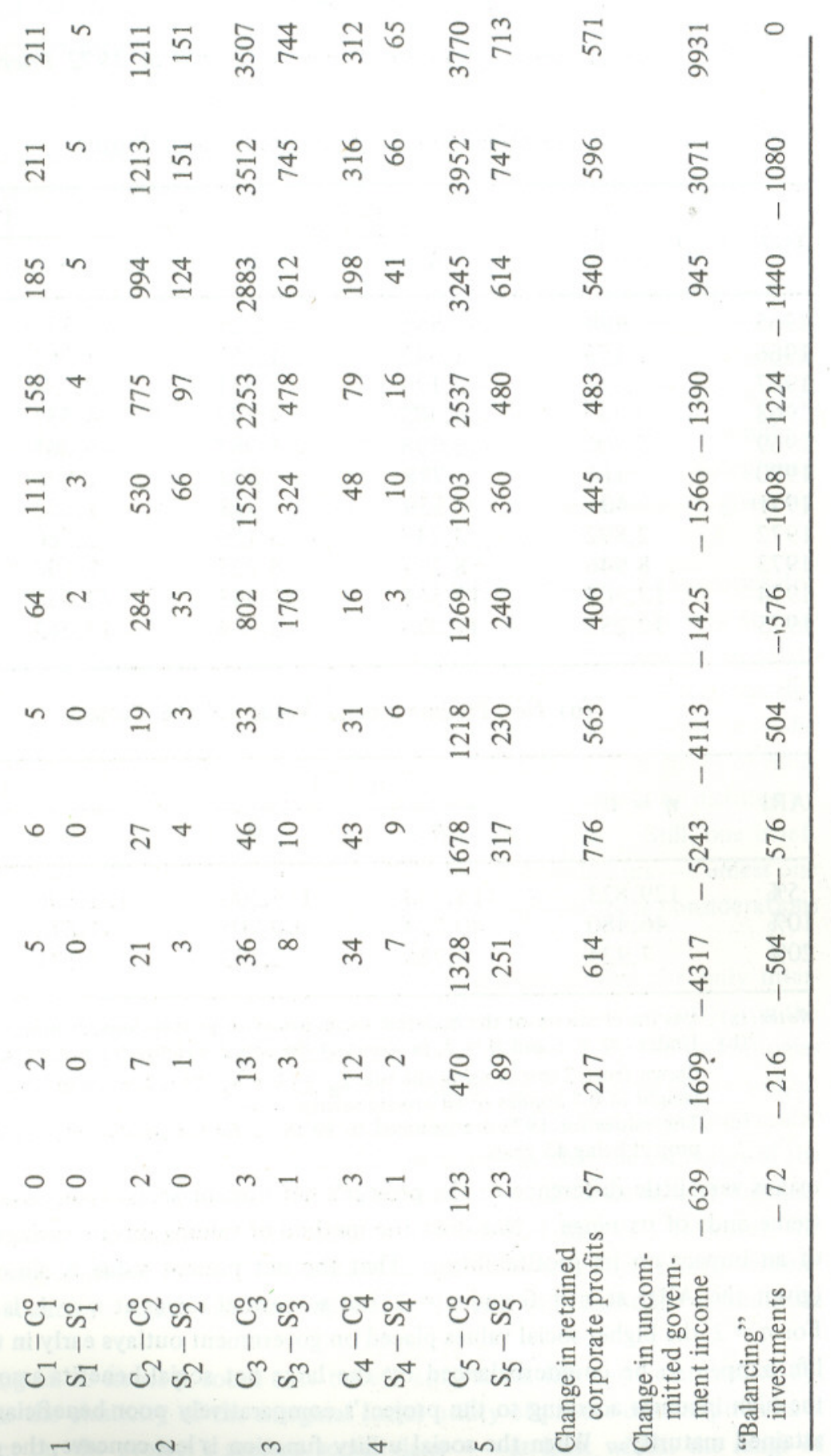


Table 5

Social Profits from the Project (M\$'000 in 1972 Prices)

(a) Stream of Undiscounted Social Profits

\begin{tabular}{|c|c|c|c|c|c|}
\hline \multirow{2}{*}{ Year } & \multirow{2}{*}{$\eta=0$} & \multicolumn{2}{|c|}{$\eta=1$} & \multicolumn{2}{|c|}{$\eta=2$} \\
\hline & & A & B & A & B \\
\hline 1965 & -498 & -548 & -525 & -553 & -529 \\
\hline 1966 & $-1,153$ & $-1,343$ & $-1,255$ & $-1,361$ & $-1,271$ \\
\hline 1967 & $-2,613$ & $-3,179$ & $-2,931$ & $-3,234$ & $-2,980$ \\
\hline 1968 & $-3,749$ & $-4,485$ & $-4,173$ & $-4,551$ & $-4,231$ \\
\hline 1969 & $-5,706$ & $-6,398$ & $-5,987$ & $-6,261$ & $-6,027$ \\
\hline 1970 & 516 & 778 & 822 & 1,979 & 1,956 \\
\hline 1971 & 405 & 539 & 533 & 1,753 & 1,659 \\
\hline 1972 & 2,892 & 3,248 & 3,159 & 2,080 & 4,899 \\
\hline 1973 & 8,946 & 8,292 & 8,225 & 9,190 & 9,111 \\
\hline 1974 & 13,505 & 12,561 & 12,443 & 13,633 & 13,502 \\
\hline 1975 & 12,253 & 11,096 & 10,969 & 12,213 & 12,068 \\
\hline
\end{tabular}

(b) Net Present Social Value of the Project

\begin{tabular}{rrrrrrr}
\hline \multirow{2}{*}{ ARI } & $\eta=0$ & \multicolumn{2}{c}{$\eta=1$} & & \multicolumn{2}{c}{$\eta=2$} \\
\cline { 3 - 4 } \cline { 5 - 7 } & & A & B & & A & B \\
\hline $5 \%$ & 129,823 & 115,743 & 115,200 & & 131,306 & 130,270 \\
$10 \%$ & 46,480 & 40,524 & 40,705 & & 47,616 & 47,501 \\
$20 \%$ & 7,924 & 5,785 & 6,183 & & 8,171 & 8,424 \\
\hline
\end{tabular}

Notes: (a) $\eta$ is the elasticity-of the marginal social utility of private consumption.

(b) Under $\eta=1$ and $\eta=2$, in case (A) the social weights for private savings $\left(\xi_{\mathrm{k}}\right)$ are drawn from Table 3 using the rule $\xi_{k}=\left[1+\lambda_{k}(\eta)\right] / 2$, while in case (B), a uniform
weight of 0.7 applies to all private

The values for 1975 ar a

project being 45 years.

makes very little difference to the project's net present social vlaue, even at the extreme ends of its range. Nor does the method of valuing private savings have much of an impact on its profitability. That the net present value is almost identical (given the ARI) at $\eta=0$ and $\eta=2$, but somewhat lower at $\eta=1$, is interesting. For $\eta=2$, the higher social values placed on government outlays early in the project's life happen to be counterbalanced by the large net social benefits associated with the high incomes accruing to the project's comparatively poor beneficiaries when it attained maturity. When the social utility function is less concave, the phasing and distribution of the stream of private incomes has such a form as to cause a reduction in the project's net present social vlaue.

\section{CONCLUSIONS}

It is clear that the analytical approach adopted here rests explicitly on the use of a simple general equilibrium model of the economy to determine a set of endogenous variables with all goods prices, domestic and foreign alike, parametrically given. Starting from an initial equilibrium for the economy, which is characterised by the conditions set out in the first section, a "project" takes the form of a sequence of disturbances in the economy's exogenous variables and underlying technology. Assuming full adjustment of the system to these exogenous changes within the unit time period which defines each point of the sequence, the time path followed by the system's variables may be forged out of the chain of comparative static equilibria corresponding to the sequence of exogenous variables. The criterion for acceptance is that the net present social value of the change in national income, as given by equation (11), should be positive.

The implicit assumption of instantaneous and full adjustment to exogenous disturbances, which entails, in this case, myopic expectations, is certainly very strong. Yet the "dual" route of using shadow prices is tarred with the same brush [14] Perhaps nothing better can be done where practical analysis is concemed, but this does not exonerate the analyst of the responsibility to be clear about what he or she is doing. Even if a truly dynamic structure were available, it is far from obvious a priori that the costs of such intrinsically difficult refinements would be justified by the improvements in practical decisions they would bring about. Still, one is left feeling uncomfortable that the results should rest on such foundations -- unless one seeks refuge in the convention that projects are small enough for these considerations not to matter.

A more particular point to emerge from the analysis is that the only interindustry linkages which have an induced -- as opposed to a direct -- effect on the determination of the endogenous variables are those expressed by the technologies for producing nontradeables. This follows immediately from the semi-input-output formulation, of course; but it does serve to highlight the fact that capturing "multiplier" effects in cost-benefit analysis requires, in principle, that the estimates of the relevant parameters pertain to the region in question. As LDCs are usually regionally heterogenous, this cannot be dismissed as a theoretical nicety. However, the analyst usually considers himself fortunate if he has access to a fairly recent national input-output table. Again, the same applies in the case of households' expenditure patterns.

Moving on to issues in social cost-benefit analysis, in this particular case study, variations in the elasticity of the marginal social utility of private consumption have little impact on the project's present social vlaue -- at least within the range of 
values considered "normal" in this literature. The project's main beneficiaries are poor, and hence socially deserving. However, the social rate of return exceeds 20 percent, even when all incomes are given the same social weight.

Once the model has been built and estimated, it can be used to evaluate any project. Computationally, nothing more than matrix inversion is needed. Even so, this invites the retort that valuing the direct inputs and outputs of a project at their (appropriate) shadow prices is more straightforward still, assuming that a set of such shadow prices is available. That, however, raises a question which goes far beyond the scope of this paper: what are the shadow prices which correspond to the primal model laid out here? This is a question we shall attempt to answer in a subsequent paper.

\section{REFERENCES}

1. Anand, Sudhir. "A Comparison of the IBRD and Little-Mirrlees Appraisal of a Highway Project in Malaysia." Washington: World Bank. 1977. (Mimeographed)

2. Atkinson, A. B. "On the Measurement of Inequality." Journal of Economic Theory. 2. September 1970. pp. 244-263

3. Bell, Clive and S. Devarajan. "A Note on Social Cost-Benefit Analysis with Multiplier Effects." Washington: World Bank. 1979. (Mimeographed)

4. Bell, C., S. Devarajan, P. Hazell and R. Slade. "A Social Accounts Analysis of the Structure of the Muda Regional Economy.” Washington: World Bank. 1976. (Mimeographed)

5. Bell, Clive and Peter Hazell. "Measuring the Indirect Effects of An Agricultural Investment Project on its Surrounding Region." Forthcoming in American Journal of Agricultural Economics. Vol. 62, No. 1. February 1980

6. Blitzer, C. R., I. M. D. Little and Lyn Squire. "Multiplier Effects and Project Evaluation." Washington: World Bank. 1978. (Mimeographed)

7. Goldman, R. N. "Staple Food Self-Sufficiency and the Distributive Impact of Malaysian Rice Policy." Minden, Penang (Malaysia): School of Comparative Social Sciences, Universiti Sains Malaysia. 1975

8. Kuyvenhoven, A. "The Integration of Project and Sector Analysis - Some Further Remarks." Oxford Bulletin of Economics and Statistics. Vol. 38, No. 1. February 1976. pp. 67-77

9. Little, I. M. D., and J. A. Mirrlees. Project Appraisal and Planning for Developing Countries. London: Heinemann Educational Books. 1974

10. Malaysia. Department of Statistics. External Trade Statistics. Kuala Lumpur. 1974

11. Scott, M. F. -G. "Shadow Wages in Mauritius." In I. M. D. Little and M. F.-G, Scott '(eds.). Using Shadow Prices. London: Heinemann Educational Books. 1976
12. Seton, F. "Shadow Prices for Chile." In R. Eckaus and P. Rosenstein-Rodin (eds.) Analysis of Development Problems: Studies in the Chilean Economy. Amsterdam: North Holland. 1973

13. Squire, Lyn and H. G. van der Tak. Economic Analysis of Projects. Baltimore: The Johns Hopkins University Press. 1975

14. Srinivasan, T. N. "General Equilibrium Theory, Project Evaluation and Economic Development.” Walras-Bowley Lecture, Econometric Society, Boulder, Colorado. 1978

15. Tinbergen, Jan. "Some Refinements of the Semi-Input-Output Method." Pakistan Development Review. Vol. VI, No. 2. Summer 1966. pp. 243-247

16. UNIDO. Guidelines for Project Evaluation. New York: United Nations. 1972

17. Veitch, M. D. "National Parameters for Project Appraisal in Malaysia." Vol. 1. Kuala Lumpur: Economic Planning Unit (EPU). 1976

18. Visaria, P. "Incidence of Poverty and the Characteristics of the Poor in Peninsular Malysia." Washington: World Bank. April 1979. (Mimeographed)

19. Wanhill, S. R. C. "A Note on the Integration of Project and Sector Analysis." Oxford Bulletin of Economics and Statistics. Vol. 36, No. 2 May 1974. pp. $109-113$ 